\title{
ADVERSE REACTIONS TO CLONIDINE IN ADHD
}

Four cases of adverse reactions to clonidine, administered alone or with methylphenidate $\mathrm{MPH}$ ), in children aged 8 to 10 years, are reported from the University of California, LA. Patient 1 taking clonidine $0.1 \mathrm{mg}$ t.i.d. and MPH 20 $\mathrm{mg}$ A.M. and $20 \mathrm{mg}$ at noon was sedated and fatigued, blood pressure and pulse rate were 16 - 30\% below baseline, ECG showed sinus bradycardia, arrhythmia, and ST elevation, and the Holter monitor revealed junctional escape rhythm, with ventricular rate of 40 while asleep. Patient 2, while on clonidine $0.1 \mathrm{mg}$ P.M. and Dexedrine $12.5 \mathrm{mg}$ daily, forgot to take one clonidine dose; after rollerblading for $10 \mathrm{~min}$ she became tremulous, had breathing and swallowing difficulty, she looked terrified, her respiration was $>100 \mathrm{~min}$, pulse $>170 \mathrm{~min}$, she became combative, had hallucinations and was disorientated and febrile. The next morning she had recovered and had amnesia for the event. Patient 3 , on clonidine $0.15 \mathrm{mg}$ P.M., MPH $50 \mathrm{mg} /$ day, and lithium, showed atrioventricular block on ECG, with PR interval lengthened from 148 to 200 msec, and bradycardia. Patient 4 had recurrent episodes of syncope related to exercise during treatment with clonidine patch, $0.2 \mathrm{mg}$ every 5 days. He complained of faintness, passed out, had convulsive movements, and died of cardiac arrest after 45 min swimming exercise. Autopsy revealed a congenital cardiac malformation with stenosis of the left coronary artery. Clonidine blood levels were "normal." (Cantwell DP, Swanson J, Connor DF. Case study: adverse response to clonidine. I Am Acad Child Adolesc Psychiatry, April 1997;36:539544). (Reprints: Dr Cantwell, UCLA NPI 48-263, 760 Westwood Plaza, Los Angeles, CA 90024).

COMMENT. The authors recommend guidelines for clonidine in treatment of ADHD that include: 1) screening for prior history of cardiac or vascular disease, a contraindication to clonidine in ADHD; 2) baseline resting pulse and blood pressure measurements, and cardiac consultation for abnormal readings, murmurs, or exercise-related syncopal symptoms; 3) dose changes should not exceed $0.05 \mathrm{mg}$ every 3 days. Until more controlled studies are completed regarding the safety of combined clonidine and stimulant therapy, polypharmacy should probably be avoided when prescibing clonidine for ADHD.

\section{HEAD TRAUMA}

\section{DIAGNOSIS AND MANAGEMENT OF CONCUSSION IN SPORTS}

The clinical validity of a standardized assessment of concussion in high school football players was confirmed at the Rehabilitation Institute of Chicago, and Northwestern University Medical School, Chicago, IL. A sideline examination, designed according to Colorado and AAN guidelines, and involving orientation in time, immediate memory for words, concentration for repeating digits and months, and delayed recall for words, was administered by athletic trainers to 141 non-injured players and 6 who suffered concussion. The concussed players as a group scored significantly below the controls and below their own baseline performance. Learning and delayed recall of a 5item word list differentiated those concussed from controls. (McCrea M, Kelly JP, Kluge J, Ackley B, Randolph C. Standardized assessment of concussion in football players. Neurology March 1997;48:586-588). (Reprints: Dr Christopher Randolph, 111 N Wabash, \#1021, Chicago, IL 60602). 